\title{
SCIENTIFIC REPORTS

\section{Survival of a long-lived single island endemic, the Raso lark Alauda razae, in relation to age, fluctuating population and rainfall}

\author{
E. G. Dierickx ${ }^{1,2}$, R. A. Robinson $\mathbb{1}^{3}$ \& M. de L. Brooke ${ }^{1 *}$
}

Estimating and understanding variation in survival rates is crucial for the management of threatened species, especially those with limited population sizes and/or restricted ranges. Using a captureresighting dataset covering 2004-2017, we estimate adult survival in the Raso lark Alauda razae, a Critically Endangered single-island Cape Verdean endemic, whose population varied 25 -fold during the study. Average annual adult survival was similar for males $(0.813 \pm 0.011)$ and females $(0.826 \pm 0.011)$ over the period. These values are high for a temperate passerine but not unusual for an insular tropical species like the lark. The oldest bird was recorded 13 years after first ringing. There was strong evidence that survival varied among years (between 0.57 and 0.95 ), being generally higher in wetter years. Survival, especially of males, was lower when the population was large, but only in drier years. Survival declined with age but there was no evidence that this decline was other than linear. High survival, even in the face of dry conditions, at least when the population is depressed, has probably contributed to the persistence of the species on its $7 \mathrm{~km}^{2}$ island home over several centuries.

Species whose distribution is confined to a single small island are inherently vulnerable to population extinction because of the risks posed by environmental and demographic stochasticity. This vulnerability is recognized in the IUCN Red List Criteria which often classify such species as Endangered, or even Critically Endangered ${ }^{1}$. Population changes are explained by the balance between reproduction and mortality which, in island endemics/ isolated island populations, is relatively easy to quantify since the populations are closed, with zero immigration and zero (or minimal) emigration. Despite their sometimes imperilled status, island populations can, therefore, offer clearer insights into the drivers of population fluctuations.

These considerations are well exemplified by the Raso lark Alauda razae of the Cape Verdes archipelago, which lies some $500 \mathrm{~km}$ west of Senegal. Since its scientific description about 120 years ago ${ }^{2}$, the lark has been confined to and survived on the uninhabited $7 \mathrm{~km}^{2}$ islet of Raso $\left(16^{\circ} \mathrm{N} 24^{\circ} \mathrm{W}\right)$, which is free of introduced vertebrate predators unlike all the other nine, permanently inhabited, Cape Verdean islands. It may be that these predators contributed to the lark's disappearance from three other Cape Verdean islands: Santo Antão, São Vicente and Santa Luzia $^{3}$. In so far as the sub-fossil record indicates a date, it seems that these disappearances were associated with the Portuguese discovery of the archipelago in 1456 and colonization six years later ${ }^{3,4}$.

During the second half of the $20^{\text {th }}$ Century, sporadic censuses suggested the Raso lark population might sometimes have fallen to as low as 20 individuals 5 . Over that time, the Cape Verdes experienced severe and sometimes prolonged droughts lasting over 10 years and resulting in the deaths of tens of thousands of people ${ }^{4,6}$. Presumably such multi-year droughts also affected Raso, and severely limited the lark's reproduction which is minimal in drought years ${ }^{7,8}$. If this is correct, the lark could only have persisted if adult survival, even in times of drought, was high. Following years of drought, the lark population can grow rapidly, doubling or tripling from one year to the next following significant rainfall through recruitment of newly-hatched individuals into the breeding population $^{7}$ (Table 1). Knowledge of how climate, particularly extreme events, can influence survival is necessary to understand how populations might respond to climates that are becoming increasingly erratic ${ }^{9,10}$. We quantify, for

${ }^{1}$ Department of Zoology, University of Cambridge, Downing Street, Cambridge, CB2 3EJ, United Kingdom. ${ }^{2}$ Fauna \& Flora International, The David Attenborough Building, Pembroke Street, Cambridge, CB2 30Z, United Kingdom. ${ }^{3}$ British Trust for Ornithology, The Nunnery, Thetford, Norfolk, IP24 2PU, United Kingdom. *email: m. brooke@zoo. cam.ac.uk 


\begin{tabular}{|l|l|l|l|l|l|}
\hline Year & $\begin{array}{l}\text { Ringed } \\
\text { males }\end{array}$ & $\begin{array}{l}\text { Ringed } \\
\text { females }\end{array}$ & All & $\begin{array}{l}\text { Of which first ringed } \\
\text { in current year* }\end{array}$ & $\begin{array}{l}\text { Total population } \\
\text { size }\end{array}$ \\
\hline 2004 & 15 & 11 & 26 & 26 & 57 \\
\hline 2005 & 41 & 18 & 59 & 38 & 132 \\
\hline 2006 & 57 & 27 & 84 & 37 & 140 \\
\hline 2007 & 58 & 41 & 99 & 23 & 159 \\
\hline 2008 & 71 & 42 & 113 & 8 & 184 \\
\hline 2009 & 65 & 47 & 112 & 24 & 193 \\
\hline 2010 & 98 & 76 & 174 & 76 & 486 \\
\hline 2011 & 158 & 140 & 298 & 114 & 1558 \\
\hline 2012 & 186 & 168 & 354 & 90 & 1546 \\
\hline 2013 & 175 & 149 & 324 & 63 & 1314 \\
\hline 2014 & 137 & 148 & 285 & 21 & 1170 \\
\hline 2015 & 101 & 161 & 262 & 92 & 900 \\
\hline 2016 & 118 & 151 & 269 & 53 & 908 \\
\hline 2017 & 179 & 208 & 387 & 142 & 1561 \\
\hline
\end{tabular}

Table 1. Male and female sample sizes, calculated as birds captured or resighted in each year of the study. Total population size is included in the table for comparison. *Excludes juveniles and nestlings.

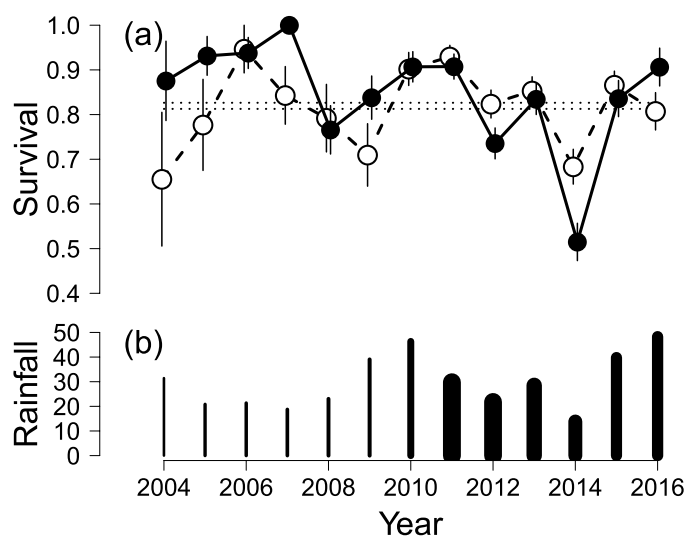

Figure 1. (a) Survival estimates for males (solid line, filled points) and females (dashed line, open points) for the time period 2004-2017, based on the model $\phi_{\text {sex*year. }}$ Error bars indicate \pm 1 s.e. and the dotted lines mean survival of females (upper) and males (lower). (b) Mean daily rainfall ( $\mathrm{mm}$ ) for Aug-Nov immediately preceding each field season; bar widths are proportional to total population size.

the first time, survival in the tropical Raso lark and explore how it varies in response to hugely varying population density and rainfall levels.

Small, closed, populations may also be more susceptible to demographic fluctuations, for example in age or sex structure. In the early years of the study, the population was strongly male-biased ${ }^{11}$, a feature of many threatened bird populations ${ }^{12}$. Since in the case of the Raso lark the bias is very unlikely to be caused by sex differences in dispersal, and there is no reason to suppose a sex bias in primary sex ratio (own unpublished data), a sex ratio bias among adult larks suggests higher survival of males. Our dataset allows investigation of whether any sex difference in survival varies over time, which may in turn contribute to understanding the causes of such survival differences. Finally, the fact that survival is high, and the birds long-lived, allows us to assess changes in survivorship with age.

\section{Results}

The average resighting probability was high, for both females $(0.87 \pm 0.01)$ and males $(0.89 \pm 0.01)$. Average annual survival probabilities were similar between the sexes (female: $\phi=0.826 \pm 0.011$; male: $\phi=0.813 \pm 0.011$ ), but there was substantial variation between years (Fig. 1). Annual survival probabilities were more similar in the latter half of the study, when population size was higher, and they were influenced by the number of birds in the population and by rainfall.

Rainfall alone accounted for $\sim 23 \%$ of this variation (Table 2), with survival being higher following years of greater precipitation $(\beta=0.22 \pm 0.04)$, and survival of males being greater in wetter years $(\beta=0.32 \pm 0.06)$ than females $(\beta=0.13 \pm 0.05)$. Population size, by itself, explained less of the variation in survival probabilities $(\sim 13 \%)$, although again the effect was strongly sex-specific with males $(\beta=-0.00062 \pm 0.00015)$ having lower survival in years with high population size, while females were seemingly not affected $(\beta=0.00017 \pm 0.00016)$. As a result, in 


\begin{tabular}{|l|l|l|l|l|}
\hline Model & Npar & Deviance & $\boldsymbol{\Delta A I C}$ & Rel. Dev. \\
\hline sex * year & $\mathbf{3 0}$ & $\mathbf{3 4 7 8 . 3}$ & $\mathbf{0}$ & $\mathbf{1}$ \\
\hline sex + year & 18 & 3507.5 & 4.72 & 0.816 \\
\hline year & 17 & 3509.8 & 5.00 & 0.800 \\
\hline sex + sex:PopSize + sex:Rain + sex:PopSize:Rain & 12 & 3532.6 & 17.6 & 0.657 \\
\hline sex + sex: PopSize + sex:Rain + PopSize:Rain & 11 & 3536.0 & 19.7 & 0.631 \\
\hline sex + PopSize + Rain + PopSize:Rain & 9 & 3553.5 & 32.5 & 0.525 \\
\hline sex + Rain + sex:Rain & 8 & 3594.6 & 71.5 & 0.265 \\
\hline sex + PopSize + sex:PopSize & 8 & 3611.7 & 93.3 & 0.128 \\
\hline sex + Rain & 7 & 3600.4 & 75.3 & 0.229 \\
\hline sex + PopSize & 7 & 3629.5 & 104 & 0.045 \\
\hline sex & 6 & 3636.6 & 110 & 0 \\
\hline
\end{tabular}

Table 2. Models of annual variation in survival of Raso larks (2004-2017, n=732). For each modelled set of covariates is given the number of parameters (Npar), the total deviance explained, AIC relative to the best model $(\triangle \mathrm{AIC})$, and the deviance relative to the full $\left(\phi_{\text {sex*year }}\right)$ and null $\left(\phi_{\text {sex }}\right)$ models (Rel. Dev.). Capitalised parameters are linear, those in lower-case factors (with 2, sex, or 13, year, levels). Models are listed in descending order of complexity and all include four re-encounter parameters ( $\mathrm{p}_{\mathrm{td} * \mathrm{sex}}$, see text).
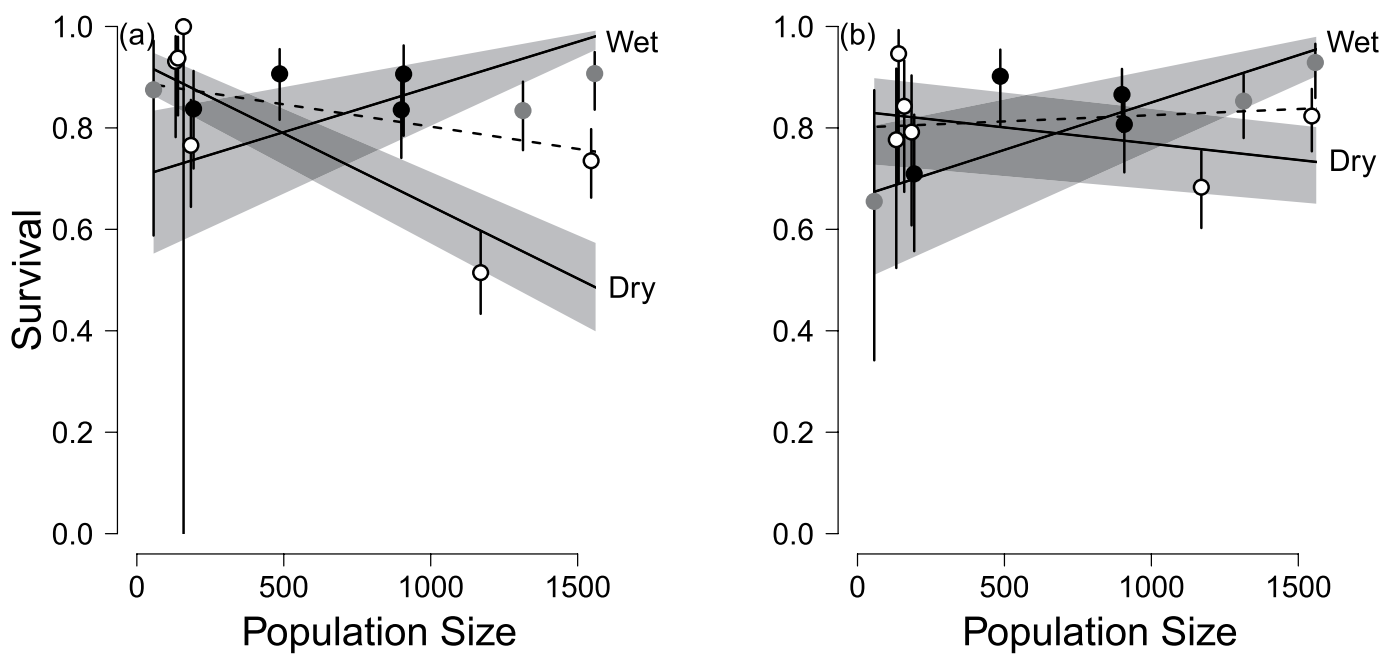

Figure 2. Survival of (a) male and (b) female Raso larks in relation to population size, according to whether the year was one of the six driest (open circles), three intermediate (grey dots) or four wettest (black dots); bars indicate \pm 1 s.e from model $\phi_{\text {sex*PopSize }+ \text { sex*Rain }+ \text { sex*PopSize*Rain. }}$. The dotted line indicates the response of survival to population size without accounting for rainfall (from model $\phi_{\text {sex*PopSize }}$ ). Shading indicates $95 \%$ confidence limits about the regression.

the nine years without strong juvenile recruitment (i.e. excluding 2004/5, 2009/10, 2010/11 and 2016/17; Table 1), annual population change was more closely related to male $(\mathrm{r}=0.86, \mathrm{p}=0.003)$ than female survival $(\mathrm{r}=0.54$, $\mathrm{p}=0.13$ ). The impact of population size on survival probabilities was most marked in dry years (Fig. 2); in combination, rainfall and population size accounted for about two-thirds of the annual variation in survival probability in the population (Table 2).

Individual survival probabilities declined with time since marking (Fig. 3), and presumed older birds (those with damaged claws on ringing) had a lower survival probability (Table 3 ). The rate of decline in survival with time since marking was higher for females $(\beta=-0.15 \pm 0.05)$ than for males $(\beta=-0.10 \pm 0.04)$, and female individuals with damaged claws consequently exhibited a greater lowering of survival $(\beta=-0.39 \pm 0.20)$ compared to those with undamaged claws than did their male counterparts $(\beta=-0.26 \pm 0.19)$, though the estimated difference was small. The decline in survival with time since marking among the claw-damaged birds was slightly higher than among (presumed) younger individuals $(\beta=-0.05 \pm 0.07)$, suggesting the possibility of an accelerated decline with increasing age, but including a quadratic TSM term in the model did not improve the fit (Table 3).

An estimate of the survival of individuals of known age indicated that survival of first-year birds $(\phi=0.63 \pm 0.05)$ was lower than that of adults, and supported a decline in survival with age (Table 4), although the estimate of the rate of decline was small $(\beta=-0.01 \pm 0.17)$. 


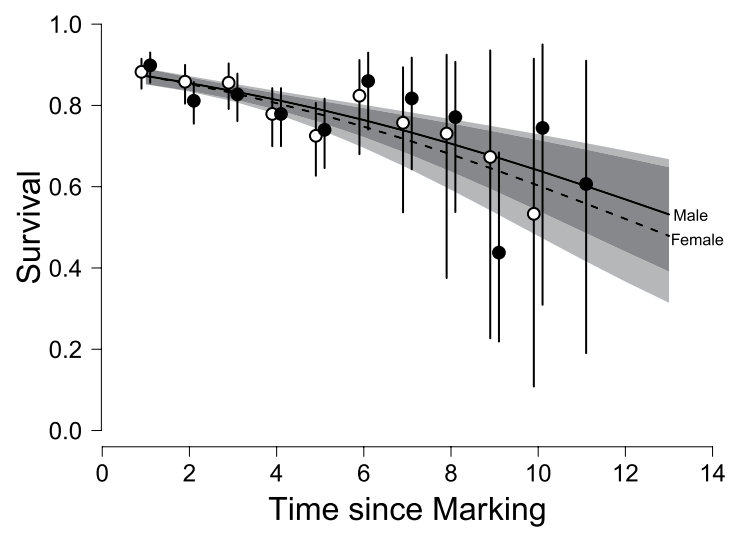

Figure 3. Modelled annual survival ( \pm 1 s.e.) of male (solid line, filled points) and female (dashed line, open points) Raso larks according to time since marking (as a proxy for age). Estimates are for birds without claw damage; those exhibiting damaged claws had a lower intercept $(\beta=-0.35 \pm 0.14)$. Shading indicates $95 \%$ confidence limits about the regression. Reading from the top, the four grey-shade boundaries represent male upper confidence limit, female upper confidence limit, male lower confidence limit, and female lower confidence limit.

\begin{tabular}{|c|c|c|c|}
\hline Model & Npar & Deviance & $\Delta$ AIC \\
\hline sex + year + sex:TSM + sex:claw & 22 & 3479.1 & 3.07 \\
\hline sex + year + sex:TSM + claw & 21 & 3479.2 & 1.17 \\
\hline sex + year + TSM + claw + claw:TSM & 21 & 3479.6 & 1.56 \\
\hline sex + year + TSM + claw & 20 & 3480.1 & 0 \\
\hline sex + year + sex:TSM & 20 & 3490.1 & 10.0 \\
\hline sex + year + TSM $+(\text { TSM })^{2}$ & 20 & 3490.6 & 10.5 \\
\hline sex + year + TSM & 19 & 3490.6 & 8.52 \\
\hline sex + year & 18 & 3507.5 & 23.4 \\
\hline
\end{tabular}

Table 3. Variation in survival among adult Raso larks $(n=732)$ with time since marking (TSM, a proxy for age) and the presence of damaged claws (indicating greater age). For each modelled set of covariates is given the number of parameters (Npar), the total deviance explained and AIC relative to the best model (highlighted). Capitalised parameters are linear, those in lower-case factors (with 2, sex and claw, or 13, year, levels). Models are listed in descending order of complexity and all include four re-encounter parameters $\left(\mathrm{p}_{\mathrm{td}{ }^{*} \mathrm{sex}}\right.$, see text).

\begin{tabular}{|l|l|l|l|}
\hline Model & Npar & Deviance & $\mathbf{\Delta A I C}$ \\
\hline year+age & 28 & 656.3 & 23.1 \\
\hline year+ Age & 17 & 662.2 & 4.33 \\
\hline year & $\mathbf{1 5}$ & $\mathbf{6 6 2 . 2}$ & $\mathbf{0}$ \\
\hline
\end{tabular}

Table 4. Survival in relation to age for birds of known age (those ringed as nestlings or juveniles, $\mathrm{n}=124$ ). For each modelled set of covariates is given the number of parameters (Npar), the total deviance explained and AIC relative to the best model (highlighted). Capitalised parameters are linear, those in lower-case factors. Models are listed in descending order of complexity and all include four re-encounter parameters ( $\mathrm{p}_{\mathrm{td} *_{\mathrm{sex}}}$, see text).

Despite the marked sexual dimorphism, there was no discernible effect of bill or wing length on annual survival of males and females, and that remained true regardless of rainfall (Table S1).

\section{Discussion}

Using a capture-resighting dataset of colour-ringed individuals observed from 2004 until 2017, we show that annual survival of adult Raso larks is generally high, but fluctuates in response to a combination of population density and rainfall. Additionally, survival was age-related, with older birds having lower survival rates, especially amongst females.

Previous studies (usually of insectivorous passerines) have shown that survival may be increased in wetter ${ }^{13,14}$ or drier ${ }^{15}$ times. Survival in the Raso lark, primarily a granivore during drier periods, was lower in drier years, in common with other granivores living in arid environments ${ }^{16,17}$, suggesting food resources may be a critical mediating factor ${ }^{18}$. Since rainfall also promotes breeding activity and larger clutches ${ }^{8}$, the implication is that there is little or no trade-off between reproduction and survival ${ }^{19,20}$ in this species. Instead, the Raso lark seems to elevate its reproductive effort to take advantage of wetter years with more resources, avoiding this trade-off. Moreover, 
the impact of rainfall per se on survival was more pronounced than that of population size, which nonetheless interacted as a factor with rainfall: in wetter years, survival was little affected by population size despite an order of magnitude variation in population size. The absence of a signal of density-dependence in these wetter years was unexpected. However, in drier years, when food was presumably scarcer, survival was depressed when the population was higher.

This study bears on two discussion strands concerning avian survival. The first focuses on the characteristics of islands and the distinct impact that they could have on the survival rates of island species. Researchers frequently describe a pattern whereby island species and island populations of widespread species have higher survival rates than their continental counterparts ${ }^{21,22}$. Compared to continental birds, island species may shift more resources towards self-maintenance as a means of increasing survival in order to maximize lifetime reproductive success; they may be able to do this because of the generally more stable, milder climates on islands and the lower prevalence of parasites and predators ${ }^{22}$. These arguments are applicable to the island of Raso, which has a fairly stable temperature, little annual variation in daylength, very few predators for the lark and, in all likelihood given its aridity, few lark parasites ${ }^{23}$.

The Raso lark's annual adult survival rate is certainly high compared to the majority of continental passerine bird species. Its closest relative, the skylark Alauda arvensis, has a trans-Palaearctic breeding distribution and a much lower annual survival rate, estimated by different researchers between 0.39 and 0.78 , with most studies placing it around $0.50-0.60^{24}$. The Raso lark's survival rate is also higher than that of the continental Dupont's lark Chersophilus dupont ${ }^{25}$, and much higher than that of most other continental passerines. Blake and Loiselle ${ }^{26}$ estimate average survival rates of forest species in Eastern Ecuador at 0.58. Peach et al. ${ }^{27}$ estimate average survival rates of granivorous southern African passerines at 0.54 , and of insectivorous and nectarivorous passerines at 0.72. In Nigeria, McGregor et al..$^{28}$ estimate the average survival rate of birds at 0.60 . Another survey reported a mean survival rate of 0.53 in North American passerines ${ }^{29}$. However, island passerines seem generally to have higher survival rates, comparable to that of the Raso lark ${ }^{21,30-32}$.

The second (highly debated) conjecture is that tropical passerines have higher survival rates than their temperate counterparts ${ }^{26,29,33}$. This conjecture is based on the fact that birds in the tropics generally lay smaller clutches than in the temperate zones, and on the inverse relationship between fecundity and survival ${ }^{29}$. It is doubtful whether this argument can be applied to the Raso lark whose survival (this study) and fecundity ${ }^{8}$ are both higher when rainfall is higher.

Although average survival of males and females was similar, the most supported model (Table 2) includes an interaction term between year and sex, suggesting that the influence of sex on adult survival varies over time. Indeed, while males seem to have had higher survival at the beginning of the study, this trend reversed between 2011 and 2015 (Fig. 1). Coupled with the population expansion derived from the recruitment of equal numbers of young males and females to the population, the reversal abolished the sex ratio bias that so prominently favoured males in the early years of the study ${ }^{11}$ (Table 1). One potential factor explaining variation in the relative survival of males and females, body size, had no discernible effect (Table S1).

Interestingly, survival of females was less influenced by both of the environmental factors we explored (rainfall and population size) than that of males. A similar result has been shown recently in a Neotropical wren, indicating that another limiting factor can over-ride local environmental effects, perhaps through the increased cost of reproduction incurred by females ${ }^{34}$. Consistent with this, the survival of females declined more with age than did that of males (Fig. 3). This implies that if there is a sustained period of low reproduction, then a male bias (as was observed in the early years of the study; Table 1) will arise demographically if recruitment is insufficient to counterbalance the higher female mortality. Thus, these results suggest that the male bias commonly reported in threatened populations ${ }^{12}$ may result from sustained low reproductive success rather than, necessarily, being induced directly by some environmental factors affecting female survival, at least in longer-lived species.

These results also suggest a possible explanation for why male survival was lower than that of females during 2011-2015. This could be a direct consequence of the reduction of the survival of males, but not of females, caused by the large population then on the island. Why the high population size should differentially impact males is not clear: one possibility is that their larger body size and metabolic needs place them at a disadvantage compared to smaller females when the population is high and competition for resources presumably most intense (although there was no evidence of differential survival between smaller and larger individuals). The phenomenon is unlikely to be caused by the cost of intrasexual competition for mates or territorial defence in males, as when the population is large and the environment is dry, birds generally forgo breeding and territory defence, and instead forage in flocks.

Older birds experienced lower survival than younger birds, a finding replicated in a number of other passerine studies ${ }^{35-37}$. Despite the fair size of our dataset, it was not possible to determine whether the decline in survival was more or less linear or whether there was an age at which the decline in survival with age abruptly steepened $^{38,39}$. Anecdotally, the fact that five birds have been observed 12 years after first capture and only one subsequently at 13 years suggests that this could be an age at which survival probabilities deteriorate sharply.

\section{Conclusion}

The Raso lark is an island-dwelling tropical species, typically with high survival. Only when a very dry year (or years) coincides with a high population is survival substantially depressed. These features enable the species to persist through several years of drought, investing in survival and only making the additional investment in reproduction when conditions once more become relatively favourable ${ }^{40}$. Such a strategy is viable because, at least for the first ten years of life, senescence approaches slowly. The features also clarify how the species has survived for several centuries on a single small island with a population at times falling below 100 . Additionally, this suggests that, in this and similar species, conservation management actions may best target reproductive potential or, 
indeed, increase the range of the species, if this has contracted historically. With this in mind, and the Raso lark facing an uncertain future, we are currently attempting to (re-) establish a second population on Santa Luzia ${ }^{41}$.

\section{Methods}

Fieldwork on raso. After trial visits in 2002 and 2003, the present study commenced in 2004 and has continued annually to 2017 with single visits each year lasting 12-20 days. These visits occurred in November or early December. This is towards the end of the period, August-November, when birds are most likely to be breeding following rainfall ${ }^{8}$. However breeding is rain-dependent and may occur at other times of year, rain permitting. This fieldwork schedule meant we encountered numerous breeding attempts but have no data on the number of attempts individual birds may make in a year.

All birds were captured and ringed under permits issued by the Direcção Nacional do Ambiente (Environment Ministry), Cape Verdes. This catching was done by M. de L. B., a fully-licensed bird ringer (British Trust for Ornithology permit A $1871 \mathrm{MP}$ ). Thanks to the species' approachability, Raso larks can be captured individually by two people carrying a mist net, fully extended and horizontal, on two poles. When a target bird is sighted, it is approached downwind and the net dropped over the bird, which is then extracted immediately. Each bird received an individually-numbered metal ring and a unique combination of three Darvic colour rings. During the 2-3 week visit to Raso in November or early December, the 2-person team caught and ringed new flying birds, recorded the colour-ring combinations of surviving birds ringed in previous years, and also ringed nestlings and juveniles ( $<3$ months old). The latter were readily recognized by their browner plumage with broader pale feather edgings.

Towards the end of each year's visit, the sustained reading of colour-rings attached in previous years consistently generated resighting rates approaching $90 \%$ (see Results). We therefore knew with fair accuracy the number of colour-ringed birds on the island, the sum of those ringed in the current year plus those ringed in previous years. The number of colour-ringed birds was corrected the following year to account for the small number (usually 15-20) of colour-ringed individuals that were spotted then but had been missed in the previous year, thus accounting for the incomplete detection of individuals. This correction is applied to the population values presented by Brooke ${ }^{7}$ that are used in our analyses. Transects conducted across the island then allowed an estimate of the proportion of birds that were colour-ringed, from which we calculated an overall population estimate. The population has varied greatly in size during the study: in the early years (until 2009), the population did not exceed 200 individuals, with a minimum of 57 recorded in 2004. After a dramatic increase from about 200 in 2009 to 1550 in 2011, the population fluctuated until 2017 but did not fall below 900 individuals (Table 1).

Survival modelling. Survival of birds over the period 2004-2017 was estimated by fitting Cormack-JollySeber (CJS) models to datasets with marked individuals ${ }^{42}$ using RMark $^{43,44}$. Initial goodness-of-fit testing (using Program RELEASE) suggested that the data fitted the CJS model acceptably $\left(\chi_{41}^{2}=55.8, p=0.062\right)$, but closer inspection revealed evidence of significant 'trap-dependence' (Test 2.CT: $\chi^{2}{ }_{10}=30.1, p<0.001$ ) with males, in particular, being more likely to be re-encountered if they had been seen the previous year. Consequently, we model resighting probabilities as sex-specific and dependent on whether the individual had been encountered in the previous year or not (i.e. four parameters). Including a time component in the resighting model did not change the survival estimates substantially. During the field period, an attempt was made to find all colour-ringed birds present on the island over a similar length of time, so we assume equal resighting rates across years. Our notation follows that of Lebreton et al. ${ }^{42}$, with a '*' indicating an interaction between covariates and a ' + ' indicating that covariates are additive (i.e. that they vary in parallel); also we use capitalised names to denote linear covariates and lower case to denote factorial covariates (thus, in our study, 'Year' explains 1 d.f. and 'year' 13 d.f.).

Annual variation in survival. We were interested in the determinants of survival between years and considered three variables: sex, population density and rainfall. All post-juvenile birds (known juvenile birds are excluded from this analysis) could be sexed on size; indeed the Raso lark is one of the most sexually dimorphic lark species, with, for example, male bills $20-25$ percent longer than those of females ${ }^{11,45}$. Rainfall has not been consistently directly measured on Raso, so we extracted an annual measure from the remote-sensed NCAR TRMM Multi-satellite Precipitation Analysis dataset (TMPA v $7^{46}$ ), which is available daily at $0.25^{\circ}$ resolution. We downloaded the monthly accumulated combined microwave-infrared data for the $5^{\circ}$ square centred on Raso and bounded by $14^{\circ} \mathrm{N} 22^{\circ} \mathrm{W}, 19^{\circ} \mathrm{N} 27^{\circ} \mathrm{W}$ for the period of the study from https://pmm.gsfc.nasa.gov/data-access/ downloads/trmm; this smooths out some of the stochasticity inherent in estimation at finer resolutions. On Raso, most precipitation occurs in the latter half of the calendar year so we summed daily totals for the period August November and related these to the survival of larks for the following year, assuming survival to be related to food resources that are determined by rainfall in this period.

We were less interested in identifying the most parsimonious model (i.e. our 'best' estimate of annual survival), than the relative importance of the different covariates in determining the observed variation in annual survival. Consequently, following Grosbois et al. ${ }^{47}$, we calculate the amount of deviance explained relative to our null model, survival constant over time but differing by sex, and the full model, survival estimated separately for each sex in each year; this measure is then analogous to the $\mathrm{R}^{2}$ metric familiar from linear regression.

Age-specific variation in survival. We looked for age-specific variation in two ways. First, with the dataset of adult captures, we looked for a relationship with time since marking (tsm), as this will correlate with age. In common with most lark species, Raso larks undergo a complete post-juvenile moult, probably when they are about three months old, after which birds of different ages cannot be distinguished, so tsm is not perfectly correlated with age as most individuals were ringed at unknown ages. It is worth noting, though, that, in years of major population expansion (e.g. a three-fold growth from 2010-2011), at least two-thirds of the birds in the population 
are one-year-old. In practice, the proportion of one-year-olds among newly-ringed birds will be high because older birds are often already ringed and trap-shy while the younger birds are naïve to trapping. Furthermore, while nestlings $(n=c 150)$, juveniles $(n=22)$ and known one-year old birds $(n=3)$ never have damaged claws or toes, approximately one-third of known age birds captured when two or older do exhibit such damage to their claws. This damage is apparently never repaired ${ }^{7}$; therefore we can treat birds first caught with damaged claws or toes as a separate group, older on average than those with undamaged claws (although the exact extent of the age difference is not known). We test both linear and non-linear quadratic forms of time since marking (TSM, TSM ${ }^{2}$ ). Since the fully parameterised model (sex * year* tsm) was not identifiable, due to sparseness of data, we do not present $\mathrm{R}^{2}$ values for these age-related models of survival.

Secondly, we looked for age-specific variation in survival of a smaller set of birds marked as pulli or newly fledged juveniles ( $n=131$, of which 83 were re-encountered after ringing). Here, we estimated survival separately in the first-year (expecting it to be lower), with survival in subsequent years as a linear function of age. As juvenile birds cannot be sexed reliably in the field, we do not include this factor in these known-age models.

Body size. Since the Raso lark is strongly sexually size dimorphic ${ }^{11,45}$, we also assessed whether body size influenced survival, independently of sex, by measuring wing length (flattened chord) and bill length from tip to base of skull. Both measurements show minimal overlap between the sexes. To minimize observer bias, all these measurements were made by M. de L. B.

Received: 14 February 2019; Accepted: 3 December 2019;

Published online: 20 December 2019

\section{References}

1. IUCN. The IUCN Red List of Threatened Species. Version 2018-2, http://www.iucnredlist.org. Downloaded on 14 November 2018 (2018).

2. Alexander, B. An ornithological expedition to the Cape Verde Islands. Ibis 4, 74-118 (1898).

3. Mateo, J. A., López Jurado, L. F. \& Geniez, P. Historical distribution of the Raso Lark Alauda razae in the Cape Verdes. Alauda 77, 309-312 (2009).

4. Donald, P. F. \& Brooke, M. de L. An unlikely survivor: the peculiar natural history of the Raso Lark. Brit. Birds 99, 420-430 (2006).

5. Donald, P. F., de Ponte, M., Pitta Groz, M. J. \& Taylor, R. Status, ecology, behaviour and conservation of Raso Lark Alauda razae. Bird Conserv. Intl. 13, 13-28 (2003).

6. Brooks, G. E. Cabo Verde: Gulag of the South Atlantic: Racism, fishing prohibitions, and famines. History in Africa 33, 101-135 (2006).

7. Brooke, M. de L. et al. Rainfall-related population growth and adult sex ratio change in the Critically Endangered Raso lark (Alauda razae). Anim. Conserv 15, 466-471 (2012).

8. Brooke, M. de L. Extreme rainfall-related clutch size variation in the Critically Endangered Raso Lark Alauda razae of the arid Cape Verde islands. Bird Conserv. Intl, https://doi.org/10.1017/S0959270918000163 (2018).

9. Saether, B. E. et al. Population dynamical consequences of climate change for a small temperate songbird. Science 287, 854-856 (2000).

10. Jenouvrier, S., Péron, C. \& Weimerskirch, H. Extreme climate events and individual heterogeneity shape life-history traits and population dynamics. Ecol. Monogr. 85, 605-624 (2015).

11. Donald, P. F. et al. Status of Raso Lark Alauda razae in 2003, with further notes on sex ratio, behaviour and conservation. Bird Conserv. Intl. 15, 165-172 (2005).

12. Donald, P. F. Adult sex ratios in wild bird populations. Ibis 149, 671-692 (2007).

13. Wolfe, J. D., Ralph, C. J. \& Elizondo, P. Changes in the apparent survival of a tropical bird in response to the El Niño Southern Oscillation in mature and young forest in Costa Rica. Oecologia 178, 715-721 (2015).

14. Rockwell, S. M. et al. Seasonal survival estimation for a long-distance migratory bird and the influence of winter precipitation. Oecologia 183, 715-726 (2017).

15. Thomas, B. R. \& Sillett, T. S. Climate, demography and lek stability in an Amazonian bird. Proc. R. Soc. B 283, 2015.2314 (2015).

16. Gibbs, H. \& Grant, P. Adult survivorship in Darwin's ground finch (Geospiza) populations in a variable environment. J. Anim. Ecol. 56, 797-813 (1987).

17. Thatcher, B. S., Krementz, D. G. \& Woodrey, M. S. Henslow's sparrow winter-survival estimates and response to prescribed burning. J. Wildlife Manage. 70, 198-206 (2006).

18. Studds, C. E. \& Marra, P. P. Linking fluctuations in rainfall to nonbreeding season performance in a long-distance migratory bird, Setophaga ruticilla. Clim. Res. 35, 115-122 (2007).

19. Stearns, S. C. Trade-offs in life-history evolution. Funct. Ecol. 3, 259-268 (1989).

20. Dobson, F. S. \& Jouventin, P. The trade-off of reproduction and survival in slow breeding seabirds. Can. J. Zool. 88, 889-899 (2010).

21. Monticelli, D. et al. High survival rate of a Critically Endangered species, the Azores bullfinch Pyrrhula murina, as a contribution to population recovery. J. Orn. 151, 627-636 (2010).

22. Covas, R. Evolution of reproductive life histories in island birds worldwide. Proc. R. Soc. B 279, 1531-1537 (2012).

23. Horrocks, N. P. C. et al. Immune indexes of larks from desert and temperate regions show weak associations with life history but stronger links to environmental variation in microbial abundance. Physiol. Biochem. Zool. 85, 504-515 (2012).

24. Donald, P. F. The Skylark. (T \& AD Poyser, 2004).

25. Vögeli, M., Laiolo, P., Serrano, D. \& Tella, J. L. Who are we sampling? Apparent survival differs between methods in a secretive species. Oikos 117, 1816-1823 (2008).

26. Blake, J. G. \& Loiselle, B. A. Estimates of apparent survival rates for forest birds in eastern Ecuador. Biotropica 40, 485-493 (2008).

27. Peach, W. J., Hanmer, D. B. \& Oatley, T. B. Do southern African songbirds live longer than their European counterparts? Oikos 93 , $235-249(2001)$

28. McGregor, R., Whittingham, M. J. \& Cresswell, W. Survival rates of tropical birds in Nigeria, West Africa. Ibis 149, 615-618 (2007).

29. Johnston, J. P., Peach, W. J., Gregory, R. D. \& White, S. A. Survival rates of tropical and temperate passerines: a Trinidadian perspective. Am. Nat. 150, 771-789 (1997).

30. Simon, J. C., Pratt, T. K., Berlin, K. E. \& Kowalsky, J. R. Reproductive ecology and demography of the'Akohekohe. Condor 103, 736-745 (2001)

31. Leech, T. J., Craig, E., Beaven, B., Mitchell, D. K. \& Seddon, P. J. Reintroduction of Rifleman Acanthisitta chloris to Ulva Island, New Zealand: evaluation of techniques and population persistence. Oryx 41, 369-375 (2007).

32. Mounce, H. L., Iknayan, K. J., Leonard, D. L., Swinnerton, K. J. \& Groombridge, J. J. Management implications derived from long term re-sight data: annual survival of the Maui Parrotbill Pseudonestor xanthophrys. Bird Conserv. Intl. 24, 316-326 (2014). 
33. Blake, J. G. \& Loiselle, B. A. Apparent survival rates of forest birds in eastern Ecuador revisited: Improvement in precision but no change in estimates. PLoS One 8, e81028 (2013).

34. Woodworth, B. K., Norris, D. R., Graham, B. A., Kahn, Z. A. \& Mennill, D. J. Hot temperatures during the dry season reduce survival of a resident tropical bird. Proc. R. Soc. B 285, 2018.0176 (2018).

35. Brown, W. P. \& Roth, R. R. Age-specific reproduction and survival of individually marked Wood Thrushes, Hylocichla mustelina. Ecology 90, 218-229 (2009).

36. Bouwhuis, S., Choquet, R., Sheldon, B. C. \& Verhulst, S. The forms and fitness cost of senescence: age-specific recapture, survival, reproduction, and reproductive value in a wild bird population. Am. Nat. 179, E15-E27 (2012).

37. Knape, J., Jonzen, N., Skold, M., Kikkawa, J. \& McCallum, H. Individual heterogeneity and senescence in Silvereyes on Heron Island. Ecology 92, 813-820 (2011).

38. Catry, P., Phillips, R. A., Phalan, B. \& Croxall, J. P. Senescence effects in an extremely long-lived bird: the grey-headed albatross Thalassarche chrysostoma. Proc. R. Soc. B 273, 1625-1630 (2006).

39. Ricklefs, R. E. Intrinsic aging-related mortality in birds. J. Avian Biol. 31, 103-111 (2000).

40. França, L. F. \& Marini, M. Â. Negative population trend for Chapada Flycatchers (Suiriri islerorum) despite high apparent annual survival. J. Field Orn. 81, 227-236 (2010).

41. Brooke, M. et al. Fieldwork report on the translocation of Raso larks from Raso to Santa Luzia, April 2018. (Unpublished report, Department of Zoology, University of Cambridge, 2018).

42. Lebreton, J. D., Burnham, K. P., Clobert, J. \& Anderson, D. R. Modeling survival and testing biological hypotheses using marked animals: a unified approach with case studies. Ecol. Monogr. 62, 67-118 (1992).

43. Laake, J. L. R Mark: An R Interface for Analysis of Capture-Recapture Data with MARK. AFSC Processed Rep 2013-01, 25pp. (Alaska Fish. Sci. Cent., Seattle, 2013).

44. White, G. C. \& Burnham, K. P. Program MARK: survival estimation from populations of marked animals. Bird Study 46, S120-139 (1999).

45. Del Hoyo, J., Elliott, A. \& Christie, D. A. Handbook of the Birds of the World, Vol. 9. (Lynx Edicions, 2004).

46. Huffman, G. J. et al. The TRMM Multisatellite Precipitation Analysis (TMPA): quasi-global multiyear, combined-sensor precipitation estimates at fine scale. J. Hydrometerol. 8, 38-55 (2007).

47. Grosbois, V. et al. Assessing the impact of climate variation on survival in vertebrate populations. Biol. Rev. 83, 357-399 (2008).

\section{Acknowledgements}

Funding for this long-term study was generously provided by Julian Francis, the Royal Society for the Protection of Birds, BirdLife International's Preventing Extinctions Initiative, the Sir Peter Scott Studentship (to E.G.D.) of Trinity College, Cambridge, the Fondation Vocatio Award (to E.G.D.), the Desertas Fund of Sociedade Caboverdiana de Zoologia (CPV/SGP/OP5Y1/CORE/BD/11/13) and the Mava Foundation. Crucial help with fieldwork came from Mark Bolton, Ewan Campbell, Simon Davies, Mike Finnie, Tom Flower, Sabine Hille, Lee Gregory, Mark Mainwaring, Jason Moss, Alex Penn and Justin Welbergen, while the logistics were facilitated by Pedro Geraldes, Ana Rodrigues, and Silvana Monteiro Roque. Our thanks to Paul Donald and Rhys Green for helpful discussion, and three anonymous referees for valuable suggestions, plus a final thank you to Pensão Jardim in São Nicolau and the fishermen of Raso.

\section{Author contributions}

The study was initiated and maintained by M.de L.B. who undertook fieldwork in all years. E.G.D. contributed to fieldwork, began the MARK analysis that was refined by R.A.R. and wrote the first draft of the paper. All authors critically revised and approved the paper.

\section{Competing interests}

The authors declare no competing interests.

\section{Additional information}

Supplementary information is available for this paper at https://doi.org/10.1038/s41598-019-55782-8.

Correspondence and requests for materials should be addressed to M.d.L.B.

Reprints and permissions information is available at www.nature.com/reprints.

Publisher's note Springer Nature remains neutral with regard to jurisdictional claims in published maps and institutional affiliations

Open Access This article is licensed under a Creative Commons Attribution 4.0 International License, which permits use, sharing, adaptation, distribution and reproduction in any medium or format, as long as you give appropriate credit to the original author(s) and the source, provide a link to the Creative Commons license, and indicate if changes were made. The images or other third party material in this article are included in the article's Creative Commons license, unless indicated otherwise in a credit line to the material. If material is not included in the article's Creative Commons license and your intended use is not permitted by statutory regulation or exceeds the permitted use, you will need to obtain permission directly from the copyright holder. To view a copy of this license, visit http://creativecommons.org/licenses/by/4.0/.

(C) The Author(s) 2019 